\title{
GNSS PRACTICE IN SURVEY DEPARTMENT
}

\author{
Sushmita Timilisina \& Bibek Nepal
}

\section{KEYWORDS}

GNSS, Reference System, PNT, CORS, Transformation Parameters

\begin{abstract}
Control Networks for Nepal was originally defined through the use of conventional measurements. Conventional mapping methods have led to a static and inactive networks of control point. This network of control served us very well until the devastating earthquake hit Nepal and disturbed it. Determination of precise ground locations is essential for various tasks such as engineering works, earth observation, location-based technologies, emergency service providers, etc. Global Navigation Satellite System plays a very important role in providing quick and reliable positioning/navigation data. The term 'global navigation satellite system' (GNSS) refers to a constellation of satellites providing signals from space transmitting positioning and timing data. These systems use the principle of trilateration to calculate the location of a user, through the information obtained from a number of satellites. Each satellite transmits coded signals at precise intervals. In principle, three satellites must be available to determine a three-dimensional $(x, y, z)$ position, additional fourth signal is necessary for precise location of a single point. This helps in eliminating the time differences between satellite's atomic clocks and the receiver's clocks. USA in around 1970's started the use of Global Positioning System(GPS). Geodetic Survey Division under Survey Department commenced the use of GPS technology in 1991 A.D as a method for survey technology. Survey Department initiated the use of GPS for carrying out survey of the previously established high order control points. Transformation Parameters (TP) between the National Co-ordinate System and WGS-84 System was derived using the initial Control points co-ordinate and co-ordinate of the same Control points obtained from GNSS survey. GNSS has been used for establishing, updating and rehabilitation of Control Network, measure shift in location produced by earthquake and for various survey task carried out by Survey Department.
\end{abstract}




\section{BACKGROUND}

The history of Surveying and mapping in case of Nepal dates back from the period Malla dynasty. Practice of keeping records about land and its type started long ago for collecting taxes. Over the time value of land has increased exponentially and so has emerged the need of accurately mapping boundaries between the land pieces. Mechanism for land measurements started from eye judgments and hand measurements progressed to tape, chains and advanced to Theodolites, EDM's, Total Stations \& GNSS. The purpose for measurement of land has shifted from fiscal purpose to legal purpose. In order to provide legal boundaries, the measurement regarding the land must be accurate. This was possible from linking the measurements with the accurate control point network. These control points form a common framework for all mapping activities and act as backbone for all surveying and mapping purposes.

Measuring, recording and registering land is a delicate and critical job and is deeply connected to the public sentiments. This huge responsibility of functioning as the national mapping agency demonstrates the importance of Survey Department in good governance in the nation. Hence, this organization has maintained a very intimate relation with general public for a long period till date.

In 2026 B.S Trigonometrical Survey Branch was established under Survey Department for establishing Control Points Network all over Nepal. Precise horizontal and vertical controls are the prerequisite in carrying out any mapping activity, hence establishment of Trigonometrical control points of different order with no vertical data deemed insufficient to fulfill the geodetic requirements. Hence, Geodetic Survey Branch was established under Survey Department in the year 2032 B.S to work on various geodetic activities like setting up Precise Leveling Network, carrying out Astronomical and Gravity Observations, defining of geoid, etc.

Control Network for Nepal was originally defined through the use of conventional measurements. Conventional mapping methods have led to static and inactive networks of control point. This network of control served us very well until the devastating earthquake hit Nepal and disturbed it. The extent of disturbance is still to be calculated. Since all measurements on land, air or water are based on national Control Network has become essential to catch up with the rapid advancement in Survey technology and use it to update the national reference system for the country.

There is a need to determine precise ground locations for use in various tasks such as engineering works, earth observation, locationbased technologies, emergency service providers, etc. Location information is vital to a large number of applications involving strategic decision making such as disaster management, earth monitoring, environment conservation, management of natural resources and food production. The global navigation satellite systems (GNSS) service is achieved by using a global network of satellites that are deployed on the space and transmits radio signals from thousands of miles above the earth. Accurate position of any point in the form of precise latitude, longitude and altitude can be achieved at any time and at anywhere around the world.

\section{INTRODUCTION}

In recent years Positioning and Navigation has become an integral part of every engineering and non-engineering field. When it comes to proper positioning/navigation satellite navigation technology plays a very important role in providing quick and reliable data. Satellitebased navigation systems use the principle of trilateration to locate the location of a user, through the information obtained from satellites. Each satellite transmits coded signals at precise intervals. In principle, three satellites must be available to determine a three-dimensional $(\mathrm{x}, \mathrm{y}, \mathrm{z})$ position. Positioning accuracy is improved with fourth satellite providing data to help eliminate the time differences between satellite's atomic clocks and the receivers' clocks.

The term 'global navigation satellite system' (GNSS) refers to a constellation of satellites providing signals from space transmitting 
positioning and timing data. By definition, a GNSS provides global coverage. GNSS receivers determine location by using the timing and positioning data encoded in the signals from space. GNSS basically is a system of satellites that provide autonomous geo-spatial positioning with global coverage. It allows electronic receivers to determine their location (longitude, latitude, and altitude) using signals transmitted by radio waves from satellites. There is a common misconception about GPS and GNSS being same. In fact, GPS is a kind of GNSS. There are several other such GNSS today. Advances in satellite technologies have yielded several navigation systems such as

- NAVSTAR GPS (Navigation System with Time and Ranging-Global Positioning System) developed by USA

- GLONASS developed by Russia

- BeiDou (BDS) developed by China

- Galileo developed by European Union

- Indian Regional Navigation. Satellite System (IRNSS) developed by India

- Quasi-Zenith Satellite System (QZSS) developed by Japan

Generally, the global coverage for each system is achieved by the constellation of 20-30 Medium Earth Orbit Satellites with the orbit inclinations of $>50^{\circ}$, satellite being at an altitude of about 19000- 20,000 kilometers orbital period of about 12 hours. In case of systems with regional coverage such as in QZSS and IRNSS the satellites are placed in geostationary orbit.

Development of hand-held receivers along with advancement in GNSS integrated system in mobile/smartphones/tablets have led to an enormous growth in application such as vehicular navigation systems, emergency and locationbased services, etc. These multiple applications have increased the need for improved accuracy, availability, continuity and integrity in the systems. Differential GNSS (DGNSS) is one possible solution for engineering grade user requirements. Correction data emitted from a known/reference station are obtained in the receiver. It is possible to achieve sub-centimeter level accuracy with high-precision receivers working with carrier phase tracking techniques. Thus, GNSS technology has become principal method for carrying out survey works.

\section{GNSS PRACTICE IN NEPAL}

USA in around 1970's. started the use of Global Positioning System(GPS) for military purpose. Geodetic Survey Division under Survey Department commenced the use of GPS technology in 1991 A.D for carrying out land survey. Survey Department initiated the use of GPS for survey of previously established high order control points. As the Reference System of the Control points established by Survey Department (in Everest 1830) does not match with the co-ordinate reference system (WGS-84) of the data obtained from GPS hence Transformation Parameters (TP) between the two-system needed to be established. This TP was computed using the initial Control points co-ordinate and co-ordinate of the same Control points obtained from GNSS survey.

\section{GNSS PROGRAMS IN SURVEY DEPARTMENT}

- Establishment of different (first/second/ third) order of controls for strengthening the geodetic network throughout the country is done on regular basis.

- Observation of previously established static control points (of different order) through the use of GNSS is done regularly as yearly development program of the department.

- During this process the description card of the control points are also revised to provide updated access route to the points.

- Survey Department is also responsible for establishing precise control points for different surveying and mapping activities as per demand. The Geodetic Survey Division has established Control Points using GNSS for cadastral survey 
in different districts as per the demand of district Survey Offices. Also, it has established control points as per the demand of several other Governmental and Non-Governmental organization.

- The devastating earthquake of 2072 caused a lot of damage to the overall Control Network of the nation. It substantiated the need in modification of the current reference System in the country. GNSS observation data collected over the period by Survey Department are currently being used to develop semi dynamic datum for the country.

- Remote Sensing Branch under Topographical Survey Division uses GNSS for setting up Ground Control Points for image rectification.

- High Precision GNSS instruments are being used in Continuously Observing Reference Station(CORS) setup with the view of periodic update of Control Network and providing continued observation for monitoring changes (deformation, seismic, etc.,). Survey Department has established first of its CORS in Nagarkot observatory.

- GNSS technique will also be adopted in height determination process of the Mt. Everest.

Data collected in the field are processed in the office using suitable parameters for adjustment of network of control points through suitable processing software. Thus, processed data are then archived in the Geodetic Database Management System (GDBMS) which was developed for storing, managing and updating geodetic data of whole country. The information regarding control points established by this department has been made available to other organizations, researchers and to the general public at minimum cost. Yearly hundreds of organizations, researchers visit Survey department for data about control point in order to use them in construction, surveys, verification of surveying tasks etc.

\section{GNSS PROCEDURE}

GNSS surveying involves collection of data (precise code and carrier phase measurements) at two or more station using GNSS equipment. Since the real-time GNSS techniques are generally considered suitable for general purpose. Static GNSS survey is carried out for establishing the control point station.

The location and distribution of survey control point station in case of GNSS survey do not depend on factors such as network shape or inter-visibility, but rather depend on sufficient redundancy to achieve the intent of the survey and any required specifications. Site selection and planning of observation sessions should aim to minimize the influence of internal and external effects.

Redundancy in the observations, absence of signal obstructions and longer observation times are well-accepted methods for minimizing the errors due to these effects. The final estimation of survey mark positions is also influenced by effect external to the GNSS measurements themselves, and surveyors should incorporate procedures for minimizing blunders by checking mark identifiers, the centering and orientation of the antenna and the measurement of antenna heights.

\subsection{Preliminaries of GNSS Survey}

The most important factor for determining GNSS station location is the requirement of project. After considering the requirements of the project the consideration must be given to the following limitations

- Station should be situated in location which are relatively free from horizon obstructions.

- A clear view of sky is required.

- Satellite do not penetrate metal, buildings or tree and are susceptible to signal delay errors when passing through leaves, glass, plastics and other 
materials

- Locations near strong radio transmission should be avoided because radio frequency transmitters, including cellular phone equipment, may disturb satellite signal reception.

- Avoid locating stations near large flat surfaces such as buildings, large signs, fences etc. as satellite signals may be reflected off these surfaces causing multipath errors.

Following are the basic field procedure followed to minimize external error factors that affect GNSS measurements

- Place station as far as possible from communication towers including mobile phone towers as they can cause interference.

- Satellite elevation mask set to $10^{\circ}$ above horizontal for field sessions

- $\quad 10$ second observation rate shall be used on observation sessions.

- Every observation must have GDOP $\leq 3$ (at least $75 \%$ of observation period).

- Ensure correct setting is available on all controllers.

- No observation shall be carried out during electrical storms (thundering/ lightening).

- Antenna are to be orientated to within $5^{\circ}$ of true north.

\subsection{GNSS survey guidelines}

The specification for GNSS field survey describe the methods and procedures that are necessary to obtain a desired accuracy to maintain the standard.

\subsubsection{GNSS survey Instruments}

\begin{tabular}{|c|c|}
\hline $\begin{array}{c}\text { GNSS survey } \\
\text { Instruments }\end{array}$ & Specification \\
\hline Technique & Static GNSS Observation \\
\hline
\end{tabular}

\begin{tabular}{|c|c|}
\hline Receiver & $\begin{array}{c}\text { Capable of receiving dual } \\
\text { frequency code and carrier } \\
\text { phase tracking }\end{array}$ \\
\hline Antenna & $\begin{array}{c}\text { Choke ring antenna/Geodetic } \\
\text { Antenna }\end{array}$ \\
\hline $\begin{array}{c}\text { Tripod and other } \\
\text { instruments }\end{array}$ & $\begin{array}{c}\text { High quality stable tripod, } \\
\text { tribrach } \\
\text { Optical plummet to ensure } \\
\text { accurate centering over marks }\end{array}$ \\
\hline
\end{tabular}

Following are the basic guidelines for observation to establish Control Stations in connection with pre-existing control Points.

- Baseline of 30-65 km shall be maintained

- Minimum observation session for shall be for 6 hours in at least two sessions.

- Occupations of the same station shall be separated by a minimum of 30 minutes between the end of one session and the start of the subsequent session (unless restarting due to an unplanned event like battery failure, tripod slip etc.)

- At least 3 (two pre-existing Control Points and one Network Control) stations shall be observed simultaneously

- The tripod must be reset with the instrument height varied by a minimum of $0.05 \mathrm{~m}$ between two occupations/ session.

- Instrument height measurements are to be independently verified at start and end of occupation/sessions.

- Photos shall be taken of all session setups.

Static GNSS survey procedures allow various systematic errors to be resolved when high accuracy positioning is required. Static procedures are used to produce baselines between stationary stations by recording data over an extended period of time during which the satellite geometry changes.

\section{PROBLEMS IN GNSS PRACTICE IN NEPAL}

Nepal has a rich geographical diversity with landscape ranging from flat lowlands of Terai 
through hills to high altitude Himalayas. This difference in landscape implies variation in ground density which indicates significant change in geoid. GNSS based surveys can vary in quality, depending on the type of GNSS receiver, antenna, equipment and observation parameters chosen. These factors are directly or indirectly affected by the geographical structure.

Generally, the higher order control points of Nepal are situated hilltop which on one hand make it safe from daily disturbances but on other make it difficult to reach with the heavy instrument. Most of these control points established are being encroached either by building communication tower or view tower. While establishing controls elsewhere, there lies the chance of getting limited number of satellite coverage and multipath error due to obstruction from hills.

\section{RECOMMENDATIONS}

The availability of high quality Positioning, Navigation and Timing (PNT) resources is becoming a matter of national security serving for effective operation of the emergency services. The provision of widely available GNSS services is an essential part of every national infrastructure. Thus, it should be cost effective to incorporate in civil GNSS receivers and free to use.
The availability of accurate and reliable information relating to the position is very critical. GNSS surveying involves the collection of precise code and carrier phase measurements recorded simultaneously at two or more survey control point station using high precision GNSS equipment. To apply proper adjustments and produce accurate output there is a need of stateof-art processing software and skilled manpower to process the data collected from field. Along with this Survey Department needs to workout proper course of action to save disturbed Control points situated atop of hills.

\section{CONCLUSION}

Besides high precision GNSS instruments/ equipment's used for engineering grade applications, integration of GNSS in smartphones, tablets etc. has made positioning and mapping task very easy and GNSS have become an integral part of our life. Nations worldwide are exploring potential growth areas for their national economy through the varied applications of satellite positioning, navigation and timing. With GNSS being more widely used for various purpose such as revenue generation or protection, there lies the possibility of growth in criminal activity aimed at disrupting the system. As for a country like Nepal without independent positioning system the policy makes should review the dependency on GNSS and prepare a strategy for developing country's independent GNSS system.

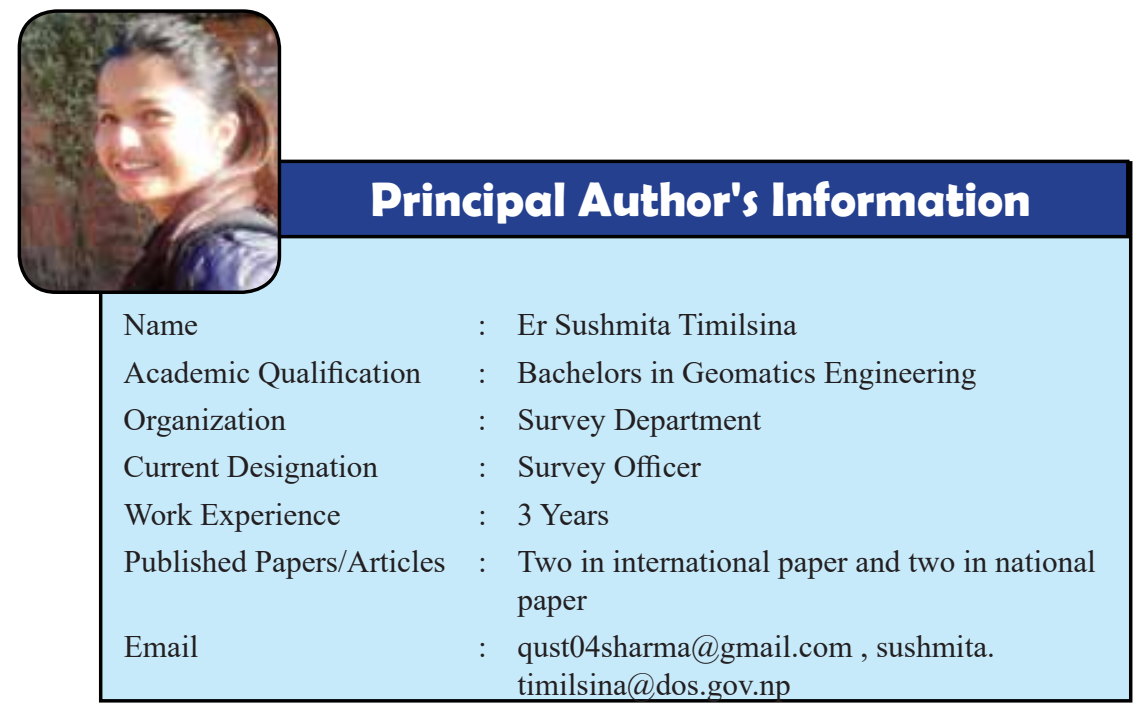

